\title{
Enhancing ear and hearing health access for children with technology and connectivity
}

\author{
De Wet Swanepoel ${ }^{1,2,3}$ \\ ${ }^{1}$ Department of Speech-Language Pathology and Audiology, University of Pretoria, South Africa. \\ ${ }^{2}$ Ear Sciences Centre, School of Surgery, University of Western Australia, Nedlands, Australia. \\ ${ }^{3}$ Ear Science Institute Australia, Subiaco, Australia.
}

\section{ABSTRACT}

Purpose: Technology and connectivity advances are demonstrating increasing potential to improve access service-delivery to persons with hearing loss. This paper demonstrates use cases from community-based hearing screening and automated diagnosis of ear disease.

Method: This brief report reviews recent evidence for school- and home-based hearing testing in underserved communities using smartphone technologies paired with calibrated headphones. A second area of potential impact facilitated by technology and connectivity is the use of feature extraction algorithms to facilitate automated diagnosis of most common ear conditions from video-otoscopic images. Results: Smartphone hearing screening using calibrated headphones demonstrated equivalent sensitivity and specificity for school-based hearing screening. Automating test sequences with a forced-choice response paradigm allowed persons with minimal training to offer screening in underserved communities. The automated image analysis and diagnosis system for ear disease demonstrated an overall accuracy of $80.6 \%$, which is on par and exceeds accuracy rates previously reported for general practitioners and paediatricians.

Conclusions: The emergence of these tools that capitalise on the technology and connectivity advances enable affordable and accessible models of service-delivery for community-based ear and hearing care. 


\section{INTRODUCTION}

Hearing loss is a major global contributor to the burden of disease with an estimated 1.33 billion people worldwide affected in 2015 it is the $2^{\text {nd }}$ most common impairment (GBD, 2016). WHO estimates, which apply a more stringent classification for hearing loss, report a global prevalence of permanent disabling hearing loss of 360 million people of whom 32 million are children (WHO, 2013). The greatest childhood $(0-14$ years of age) prevalence is in South Asia, Asia Pacific and in sub-Saharan Africa where between 1.9 and $2.4 \%$ suffer from permanent disabling hearing loss (better ear loss $>30 \mathrm{~dB}$ pure tone average; WHO, 2012).

The impact of childhood hearing loss is pervasive, affecting development across various domains including language, socio-emotional functioning, and academic outcomes (AAA, 2011). In addition to these individual effects, families are also profoundly affected (Zaidman-Zait et al. 2015) along with societal related to productivity and services (Barton et al. 2006; Mohr et al. 2000). Prevention and minimization of the consequences linked to childhood hearing loss require early identification followed by timely and appropriate interventions (Yoshinaga-Itano et al. 1998; WHO, 2013). In fact, as much as $60 \%$ of childhood hearing losses could be prevented through primary and secondary preventative measures (WHO, 2013). In cases of Otitis media, it can often be treated medically or by surgical means whilst sensorineural hearing loss requires amplification strategies alongside therapeutic interventions (WHO, 2013).

Unfortunately, early detection of hearing loss remains inaccessible for more than $80 \%$ of the world's children who reside in developing countries (WHO, 2013) due to various challenges including the shortage of ear and hearing health providers and the prohibitive costs associated with test equipment (Swanepoel et al. 2010; Clark \& Swanepoel, 2014).

\section{NEW SERVICE-DELIVERY MODELS}

Considering the widespread prevalence of hearing loss and the limited access to hearing health, alternative service-delivery models have been investigated. There has been growing interest in recent years to utilize community-based programmes 
incorporating mHealth technologies (Yousuf-Hussein et al. 2016; Sandstrom et al. 2016; Louw et al. 2016). mHealth has been broadly defined as any use of mobile technology to address healthcare challenges such as access, quality, affordability, matching of resources, and behavioral norms (Qiang et al. 2012). The field of mHealth, which demonstrates promise to improve not only access but the well-being of people around the world, is particularly appealing for low and middle income countries where mobile phone connectivity penetration exceeds $90 \%$ (Kelly \& Minges, 2012; Clark \& Swanepoel, 2014).

The reach of mobile connectivity and advanced power of smartphones offer new ways of delivering accurate and reliable clinical services on low-cost devices that can be operated by minimally trained persons such as lay community workers (Clark \& Swanepoel, 2014; Yousuf-Hussein et al. 2016). In addition to the access and cost benefits these mobile point of care diagnostics can provide comprehensive solutions that include utilisation of smartphone sensors that can, for example, ensure environmental noise monitoring for onsite quality control (Swanepoel et al. 2014), pinpoint geolocation for cloud-based patient management and referrals to closest providers. The low comparative cost of these technologies and minimal training required facilitate decentralised prevention services within communities for increased reach and impact (Yousuf-Hussein et al. 2016).

\section{Community-based screening for hearing loss}

In low- and middle-income countries newborn hearing screening is unavailable to most children (Olusanya et al. 2007). The first opportunity for systematic screening for hearing loss thereafter is at school-entry. In South Africa for example an Integrated School Health Policy (ISHP, 2012) requires all children entering the school system to have their hearing screened. Despite being policy, this service is not being realised for the vast majority of children due to factors including prohibitive equipment costs, shortage of audiometry-trained school health nurses and excessive false positives due to unmonitored environmental noise.

In response to these challenges the hearScreen development project was launched with the aim of utilizing low-cost Android smartphones paired with calibrated headphones for school-based testing. The software application developed, 
demonstrated that accurate calibration and real-time noise monitoring was possible and allowed for clinically valid pure tone audiometric screening (Swanepoel et al. 2014). Comparisons to conventional threshold audiometry further support the accuracy of testing with calibrated headphones linked to a smartphone (van Tonder et al. 2017; Sandström et al. 2016) Recommended hearing screening protocols are pre-programmed (American Academy of Audiology, 2011) for automated testing requiring only a presentation by test facilitators followed by a forced-choice option (YES/NO) on whether a child demonstrated a behavioural response.

In a clinical validation study in school children, Mahomed-Asmail et al. (2016) reported that the hearScreen smartphone hearing screening performance (sensitivity and specificity) was equivalent to conventional pure tone audiometry with significantly faster test time (Table 1). Close to $8 \%$ of screening instances at $1 \mathrm{kHz}$ was performed with noise levels exceeding maximum permissible ambient noise levels for the headphone (van der Aerschot et al. 2016) as monitored by the smartphone during tests (Mahomed-Asmail et al. 2016). Considering that ambient noise levels is one of the most common concerns in hearing screening programs (American Academy of Audiology 2011) real-time feedback on compliance to maximum permissible ambient noise levels provides environmental quality control. In a subsequent study the smartphone hearing screening was conducted by community health workers (CHWs) in an underserved South African community as part of their routine home visits. The $\mathrm{CHWs}$ had a single 4-hour training session on the smartphone screening after which they could conduct successful screening on children and adult as part of their home visits (Yousuf-Hussein et al. 2016). Environmental noise levels in this underserved community were however noted as a challenge to test at $1 \mathrm{kHz}$ and may suggest employing alternative screening protocols focussing on higher frequencies less affected by background noise. CHW's were positive about providing community-based hearing screening and reported that usability and time efficiency was good (Yousuf-Hussein et al. 2016). In another study, Louw and colleagues (2016) also evaluated the use of this smartphone audiometry application at primary health care clinics in underserved communities demonstrating that accurate $(82 / 83 \%$ sens/spec) and time efficient testing $(<1$ minute average for adults) could be conducted. 
Table 1 Smartphone (hearScreen ${ }^{\mathrm{TM}}$ ) test performance for school-based hearing screening (Mahomed et al. 2016)

\begin{tabular}{|l|c|c|}
\hline & $\begin{array}{c}\text { Conventional } \\
\text { audiometric screening }\end{array}$ & $\begin{array}{c}\text { Smartphone screening } \\
\text { (hearScreen }^{\text {TM }} \text { ) }\end{array}$ \\
\hline Sensitivity & $75 \%$ & $75 \%$ \\
\hline Specificity & $97 \%$ & $99 \%$ \\
\hline Positive Predictive value & $37 \%$ & $53 \%$ \\
\hline Negative Predictive value & $99 \%$ & $99 \%$ \\
\hline Average test time (SD) & 62.2 seconds (38.1 SD) & 54.5 seconds (28.3 SD) \\
\hline
\end{tabular}

The point of care screening provided by the smartphone application is supported by a secure cloud-based data management service (compliant with privacy protection requirements) that allows for automated text message or email reports to caregivers (Yousuf-Hussein, 2016). Furthermore, referral centres can be linked for direct referrals based on geolocation of the test. This platform also allows for surveillance and follow-up purposes and advanced reporting on outcomes for mass screening programmes. If a rescreen is conducted at referral centres with the same application this can be linked to patient records to indicate follow-up returns.

\section{Automated diagnosis for ear disease}

Ear disease is an important contributor to childhood hearing loss and resultant failures in school-based screening programs. Otitis media is one of the most common childhood diseases, especially in developing countries, making it a significant contributor to the burden of chronic disease in low and middle-income countries (Global Burden of Disease Study 2013 Collaborators, 2015; WHO, 2004). Unfortunately, access to health specialists who can provide accurate diagnoses in these world regions is typically unavailable (Fagan and Jacobs, 2009; World Health Organization, 2013). As a result, there has been increasing interest to develop image analysis systems for video-otoscopic pictures to provide an automated diagnosis (Kuruvilla et al. 2013; Myburgh et al. 2016). In a recent investigation Myburgh and colleagues (Myburgh et al. 2016) developed an image analysis system using feature extraction algorithms and a decision-tree for automated diagnosis of five most common ear conditions (i.e. acute otitic media, chronic suppurative otitis media, otitis media with effusion, wax obstruction and normal). The diagnostic accuracy of this system was $80.6 \%$ showing a substantial agreement (kappa 0.76 ; $95 \% \mathrm{Cl} 0.66$ - 
0.86 ) with expert ENT diagnoses. The classification system's accuracy compared favourably to previous reports of classification accuracy by general practitioners and paediatricians (Blomgren and Pitkäranta, 2003; Jensen and Louis, 1999) using traditional otoscopes. Using video-otoscopes to capture quality images can be facilitated by minimally trained persons (Biagio et al; 2013; Biagio et al. 2014) and could increase the reach of accurate diagnoses to direct medical or audiological treatment for children timeously. We are currently adapting the low-cost videootoscope reported by Myburgh and colleagues (2016) to a smartphone-based version that will allow uploading images to a centralised server for processing towards an automated diagnostic classification that can be sent back to the smartphone operator to assist further care decisions.

\section{CONCLUSION}

The increasing advances in technology and connectivity are opening new frontiers in ear and hearing health. It is not only that new tools are emerging for mobile point-ofcare tests linked to centralised data-management portals, but these tools are enabling new models of service-delivery for community-based ear and hearing health care utilising persons with minimal training. For children with hearing loss, especially those living in low- and middle-income countries, these developments are making community-based detection of ear and hearing disorder affordable and accessible with the promise of improved outcomes.

\section{REFERENCES}

American Academy of Audiology (AAA) (2011). American academy of audiology childhood hearing screening guidelines. Retrieved 01 May 2015 from www.cdc.gov/ncbddd/hearingloss/documents/aaa_childhoodhearingguidelines_2011.pdf

Barton, G.R., Stacey, P.C., Fortnum, H.M., Summerfield, A.Q. (2006). Hearingimpaired children in the United Kingdom, IV: cost-effectiveness of pediatric cochlear implantation. Ear and Hearing, 27(5): 575-88. 
Biagio, L., Swanepoel, D., Adeyemo, A., Hall, J.W. III, Vinck, B. (2013).

Asynchronous video-otoscopy by a telehealth facilitator. Telemedicine and e-Health, $19(4): 252-258$

Biagio, L., Swanepoel, D., Laurent, C., Lundberg, T. (2014). Video-otoscopy recordings for diagnosis of childhood ear disease using telehealth at primary health care level. Journal of Telemedicine and Telecare, 20(6):300-306.

Blomgren, K., Pitkäranta, A. (2003). Is it possible to diagnose acute otitis media accurately in primary health care? Family Practice, 20:524-7

Clark, J. L., \& Swanepoel, D. W. (2014). Technology for hearing loss - as we know it, and as we dream it. Disability and Rehabilitation Assistive Technology, 9(5), 408413. doi:10.3109/17483107.2014.905642

Fagan, J.J., Jacobs, M. 2009. Survey of ENT services in Africa: Need for a comprehensive intervention. Global Health Action, 2: 1-7

World Health Organization 2013. Multi-country Assessment of National Capacity to Provide Hearing Care. Geneva : Switzerland. Retrieved from: http://0 www.who.int.innopac.up.ac.za/pbd/publications/WHOReportHearingCare_Englishwe b.pdf

Global Burden of Disease Study 2013 Collaborators (2015). Global, regional, and national incidence, prevalence, and years lived with disability for 301 acute and chronic diseases and injuries in 188 countries, 1990-2013: a systematic analysis for the Global Burden of Disease Study 2013. Lancet, 386(9995):743-800 http://dx.doi.org/10.1016/S0140-6736(15)60692-4

GBD 2015 Disease and Injury Incidence and Prevalence Collaborators (2016). Global, regional, and national incidence, prevalence, and years lived with disability for 310 diseases and injuries, 1990-2015: a systematic analysis for the Global Burden of Disease Study 2015. Lancet, 388:1545-602. 
Integrated School Health Policy (ISHP) 2012. Department of Basic Education and Department of Health. Pretoria, South Africa. Available from: http://0www.doh.gov.za.innopac.up.ac.za/docs/policy/2012/Integrated_School_Health_Polic y.pdf

Jensen, P.M., Louis, J. (1999). Criteria, performance and diagnostic problems in diagnosing acute otitis media. Family Practice,16:262-8

Kelly, T., Minges M. (2012). Executive summary. Maximizing Mobile. Washington: International Bank for Reconstruction and Development/ The World Bank. Retrieved November 19, 2015, from http://www.worldbank.org/en/topic/ict/publication/ic4d2012.

Kuruvilla, A., Shaikh, N., Hoberman, A., Kovacevic, J. (2013). Automated diagnosis of otitis media: Vocabulary and grammar. International Journal of Biomedical Imaging, 2013:1-15 http://dx.doi.org/10.1155/2013/327515

Louw, C., Swanepoel, D., Eikelboom, R.H., Myburgh, H.C. (2016). Smartphonebased hearing screening at primary health care clinics. Ear and Hearing, [Epub ahead of print]

Mahomed-Asmail, F., Swanepoel, D., Eikelboom, R.H., Myburgh, H.C., Hall, J.W. III (2016). Clinical validity of hearScreen ${ }^{\mathrm{T}}{ }^{\mathrm{m}}$ smartphone hearing screening for school children. Ear and Hearing, 37:e11-17.

Meyer, M., Swanepoel, D., le Roux, T., van der Linde, M. (2012). Early detection of infant hearing loss in the private health care sector of South Africa. International Journal of Pediatric Otorhinolaryngology, 76:698-703.

Mohr, P.E., Feldman, J.J., Dunbar, J.L. McConkey-Robbins, A., Niparko, J.K., Rittenhouse, R.K., Skinner, M.W. (2000). The societal costs of severe to profound hearing loss in the United States. International Journal of Technology Assessment in Health Care 16(4):1120-1135. 
Myburgh, H,C,, van Zijl, W.H., Swanepoel, D., Hellström, S., Laurent, C. (2016). Otitis media diagnosis for developing countries using tympanic membrane imageanalysis. EBioMedicine 5:156-60

Olusanya, B., Swanepoel, D., Castillo, H., Chap-chap, M.J., Habib, H., Mukari, S.Z., Martinez, N.V., Lin, H.C., McPherson, B. (2007). Progress towards early detection services for infants with hearing loss in developing countries. BMC Health Services Research 7:14.

Qiang, C. Z., Yamamichi, M., Hausman, V., Miller, R., \& Altman. D. (2012). Mobile applications for the health sector. ICT Sector Unit, World Bank, Washington, DC. Retrieved 07 March 2014 from www.siteresources.worldbank.org/INFORMATIONANDCOMMUNICATIO

Sandström, J., Swanepoel, D., Myburgh, H.C., Laurent, C. (2016). Smartphone threshold audiometry in underserved primary health-care contexts. International Journal of Audiology, 55:232-238.

Swanepoel, D., Clark, J.L., Koekemoer, D., Hall, J.W., Krumm, M., Ferrari, D., McPherson, B., Olusanya, B., Mars, M., Russo, I., Barajas, J. (2010). Telehealth in audiology - the need and potential to reach underserved communities. International Journal of Audiology, 49:195-202.

Swanepoel, D. W., Myburgh, H. C., Howe, D. M., Mahomed, F., \& Eikelboom, R. H. (2014). Smartphone hearing screening with integrated quality control and data management. International Journal of Audiology, 53, 841-849.

doi:10.3109/14992027.2014.920965

Theunissen, M., Swanepoel, D. (2008). Early hearing detection and intervention services in the public health sector of South Africa. International Journal of Audiology, 47:S23-S29.

Van der Aerschot, M., Swanepoel, D., Mahomed-Asmail, F., Myburgh, H.C., Eikelboom, R.H. (2016). Affordable headphones for accessible screening 
audiometry: an evaluation of the Sennheiser HD202 II supra-aural headphone. International Journal of Audiology, 55:616-622

Van Tonder J, Swanepoel D, Mahomed F, Myburgh HC, Eikelboom RH (2017). Automated smartphone threshold audiometry: Validity and time-efficiency. Journal of the American Academy of Audiology, 28(3):200-208.

World Health Organization (2004). Chronic suppurative otitis media. Burden of illness and management options. Geneva: World Health Organization, http://www.who.int/iris/handle/10665/42941 [Accessed on 10 Nov 2016].

World Health Organisation (2012). WHO global estimates on prevalence of hearing loss - World Health Organization. http://www.who.int/pbd/deafness/WHO_GE_HL.pdf [Accessed on 10 Nov 2016].

World Health Organisation (2013). WHO | Deafness and hearing loss. Retrieved from http://www.who.int/mediacentre/factsheets/fs300/en/ [Accessed on 10 Nov 2016].

Zaidman-Zait, A., Most, T., Tarrasch, R., Haddad-Eid, E., Brand, D. (2015). The impact of childhood hearing loss on the family: mothers' and fathers' stress and coping resources. Journal of Deaf Studies and Deaf Education, 21(1): 23-33.

Yoshinaga-Itano, C., Seday, A.L., Coulter, D.K., Mehl, A.L. (1998). Language of early- and later-identified children with hearing loss. Pediatrics, 102(5): 1161-71.

Yousuf-Hussein. S., Swanepoel, D., Biagio de Jager, L., Myburgh, H., Eikelboom, R.H., Hugo, J. (2016). Smartphone hearing screening in mHealth assisted community-based primary care. Journal of Telemedicine and Telecare, 22(7):405412. 